Article

\title{
Liquid Phase Selective Hydrogenation of Phenol to Cyclohexanone over Electrospun Pd/PVDF-HFP Catalyst
}

\author{
Ahmed Abutaleb ${ }^{1, *}$, Dinesh Lolla ${ }^{2}$, Abdulwahab Aljuhani ${ }^{3}$, Hyeon Ung Shin ${ }^{4}$, \\ Mohammad Ashraf Ali ${ }^{1}$ (D), Aymen Ahmed Yousef Hassan 1,5 (D), \\ Ibrahim Mohammed Hassan Maafa ${ }^{1}$ and George G. Chase ${ }^{6}$ \\ 1 Department of Chemical Engineering, Jazan University, Jazan 45142, Saudi Arabia; \\ maali8000@gmail.com (M.A.A.); aymanyousef84@gmail.com (A.A.Y.H.); maafa94@gmail.com (I.M.H.M.) \\ 2 Biosciences and Water Filtration Division, Parker-Hannifin Corporation, Oxnard, CA 93030, USA; \\ dinesh.lolla@parker.com \\ 3 Department of Chemical Engineering, Royal Commission Yanbu Industrial College, \\ Yanbu 46452, Saudi Arabia; juhaniab@rcyci.edu.sa \\ 4 Exhaust Emission Engineering Team, Hyundai Motor Company, Gyeonggi-do 100NN, Korea; \\ hushin@hyundai.com \\ 5 Department of Mathematics and Physics Engineering, Faculty of Engineering in Matteria, Helwan \\ University, Cairo 11718, Egypt \\ 6 Department of Chemical and Biomolecular Engineering, The University of Akron, Akron, OH 44325, USA; \\ gchase@uakron.edu \\ * Correspondence: azabutaleb@jazanu.edu.sa or engahmedabutaleb@gmail.com
}

Received: 9 February 2019; Accepted: 25 March 2019; Published: 3 April 2019

\begin{abstract}
Cyclohexanone is an important industrial intermediate in the synthesis of materials such as nylons, but preparing it efficiently through one-step hydrogenation of phenol is hindered by over-reduction to cyclohexanol. Using an efficient catalyst can enhance the selectivity of cyclohexanone at high phenol conversion. In this study, catalysts comprised of palladium nanoparticles supported on electrospun PVDF-HFP (polyvinylidene fluoride-co-hexafluoropropylene) nanofibers were prepared using the electrospinning technique. The catalysts were characterized using thermogravimetric analyzer (TGA), scanning electron microscopy (SEM), transmission electron microscope (TEM), and drop shape analyzer (DSA). The prepared catalysts were used to hydrogenate phenol into cyclohexanone in a batch reactor. The Pd/PVDF-HFP catalyst showed a very high product selectivity and high phenol conversion. The conversion of phenol achieved was $98 \%$ with $97 \%$ cyclohexanone selectivity in $7 \mathrm{~h}$ using $15 \mathrm{wt} \%$ of palladium ( 0.0021 moles) relative to phenol ( 0.0159 moles). The turnover number (TON) and turnover frequency (TOF) values calculated were 7.38 and $1.05 \mathrm{~h}^{-1}$, respectively. This paper presents original research in heterogeneous catalysis using novel electrospun nanofibers. Multiphase hydrogenation of phenol to cyclohexanone over electrospun Pd/PVDF-HFP catalyst has not been reported by any researcher in the literature. This work will also provide a research window for the application of electrospun polymeric nanofibers in multiphase reactions.
\end{abstract}

Keywords: phenol to cyclohexanone; electrospun catalyst; palladium nanoparticles; multiphase reactions; nanofibers

\section{Introduction}

Cyclohexanone is an important chemical and it is a raw material used to produce $\varepsilon$-caprolactam and adipic acid. Nylon6 and nylon66 are produced from $\varepsilon$-caprolactam and adipic acid respectively [1-18]. 
Oxidation of cyclohexane [7,8] and hydrogenation of phenol [1-6,9-16,18-23] are the main two reactions that produce cyclohexanone commercially. The first route generates undesirable byproducts due to high temperatures and pressures $[15,18]$. These byproducts lower the product selectivity and make the recovery/separation steps more difficult $[15,18]$. In the hydrogenation of phenol, cyclohexanone is produced either in a "two-step" or a "one-step" process. In the two-step process, first phenol undergoes hydrogenation to produce cyclohexanol, which further dehydrogenates to form cyclohexanone $[1,10,14,15,17,18,23]$. The one-step method is preferable since it eliminates the endothermic dehydrogenation step by directly and selectively hydrogenating phenol into cyclohexanone [18]. However, cyclohexanone can hydrogenate easily to cyclohexanol and other byproducts due to its high reactivity $[1,10,14,15,17,18,23]$. Generally, vapor phase phenol hydrogenation to cyclohexanone is carried out with palladium type catalysts such as $\mathrm{Pd} @ \mathrm{Al}_{2} \mathrm{O}_{3}, \mathrm{Pd} @ \mathrm{MgO}$, and others $[3,4,9,10,15,18,20,22]$. However, deactivation by coke deposition of $\mathrm{Al}_{2} \mathrm{O}_{3}$-supported Pd catalysts can take place easily at high temperatures. Furthermore, the poor mechanical performance of $\mathrm{MgO}$ limits its use as a catalytic support in industrial application $[5,14,15,18]$. Liquid phase hydrogenation of phenol to cyclohexanone is in great interest since the reaction can be carried out at mild conditions. The capital cost can be improved effectively by having better product quality, reducing the catalyst deactivation, and operating at lower temperature and pressure. However, most of the catalysts suffered from the poising effect in the liquid phase, and a longer time is required to obtain high phenol conversion $[1,2,5,9,12-14,16,20,23]$.

Selectivity and activity of a catalyst in the hydrogenation of phenol to cyclohexanone are influenced by the metal loading, the acidity and basicity of the support, the existence of the alkali and/or alkaline earth metal, the nature of the palladium catalyst precursor, the catalyst preparation method, and the reactant concentrations $[5,6,9,11,13,15]$. Many research efforts have been put forward looking for good phenol hydrogenation catalysts. Metals including palladium (Pd) $[1,6,9,14,15,19,21]$, platinum $(\mathrm{Pt})$ [11], and ruthenium $(\mathrm{Ru})$ [4] supported on different materials such as aluminum oxide $\left(\mathrm{Al}_{2} \mathrm{O}_{3}\right)$, silicon dioxide $\left(\mathrm{SiO}_{2}\right)$, and carbon $(\mathrm{C})$ have been prepared and examined for their catalytic properties. Huizhen Liu et al. showed that a combination of two common commercial materials: (1) palladium nanoparticles supported on carbon, alumina, or NaY zeolite, and (2) a Lewis acid such as $\mathrm{AlCl}_{3}$ synergistically promotes hydrogenation of phenol to cyclohexanone [1]. They achieved phenol conversion exceeding $99.9 \%$ with $>99.9 \%$ selectivity within $7 \mathrm{~h}$ at $1.0 \mathrm{Mpa}$ hydrogen pressure and $50{ }^{\circ} \mathrm{C}$. It was demonstrated that the reaction could be carried out effectively at temperatures as low as $30{ }^{\circ} \mathrm{C}$, and $>99.9 \%$ conversion of phenol can be achieved with $>99.9 \%$ selectivity to cyclohexanone. However, the hydrogen pressure was high $(1 \mathrm{Mpa}=9.9 \mathrm{~atm})$ which imposed safety concerns and rigid reactor design-requirements. They also used dichloromethane as a solvent for phenol and not water; it is not preferred based on green chemistry. Most importantly, the existence of Lewis acids as promoters inhibits the usage of these catalysts in industry. It is not practical to use these catalysts in hydrogenation applications in general because they add other chemical sensitivities restricting substrates, purities, and reaction conditions.

A mixture of Pd-Ce-B supported on Hydrotalcite was prepared by Jianliang and co-workers [20]. They found that the incorporation of Ce could effectively enhance both the reaction rate and the cyclohexanone selectivity. These researchers suggested that Ce improved Pd dispersion on the support leading to better catalyst performance. Also, the adsorption and activation of the reactants increased when adding $\mathrm{Ce}$ since $\mathrm{Ce}^{3+}$ species can act as Lewis basic sites, which lead to an increase in the intrinsic activity. Moreover, they believed that phenol adsorption on their catalyst was in a nonplanar form which favored the synthesis of the desired product. The maximum selectivity achieved in their study was $86 \%$ in $6 \mathrm{~h}$, which is considered low. They also could not reach a complete phenol conversion. In addition, they used a high hydrogen pressure of $1 \mathrm{Mpa}$, and the solvents for phenol were ethanol and water. Most recently, $\mathrm{Xu}$ Yang and his group prepared Pt nanoparticles supported on mesoporous silica (MS), titanate nanotubes (TNT) [11]. They have also modified the TNT structure hydrophobically to entrap the Pt nanoparticles. Their modified entrapped Pt on TNT showed better performance 
compared to the other two prepared catalysts, $\mathrm{Pt} / \mathrm{MS}$ and Pt/TNT. The reaction conditions were moderate $\left(50{ }^{\circ} \mathrm{C}\right.$ and $\left.0.5 \mathrm{MPa}\right)$. However, the reaction was done using dichloromethane as a solvent, and the highest selectivity achieved was $85 \%$. Tieyong $\mathrm{Xu}$ et al. prepared palladium particles on carbon nanotubes [16]. They modified the surface of the carbon support with oxygen-containing groups (OCGs) to change the catalytic support properties. Even though the reaction time was very short compared to most other studies and water was used as a solvent, the phenol concentration was low $(13 \mathrm{~g} / \mathrm{L})$ and the hydrogen pressure was high (1 Mpa). Most importantly, the best-achieved selectivity in this study was $87.3 \%$. Yolanda Perez's group studied the effect of the support on hydrogenation of phenol in the aqueous phase [24]. They used different supports, which were alumina $\left(\gamma-\mathrm{Al}_{2} \mathrm{O}_{3}\right.$, acidic properties), carbon $(\mathrm{C})$, alumina with high surface area $\left(\mathrm{Al}_{2} \mathrm{O}_{3}-\mathrm{CWE}\right)$ and hydroxyapatite (HA), and studied the effect of the nanocrystals size Pd on catalytic properties. The results were very encouraging in terms of conversion and selectivity. They found higher selectivity and activity to cyclohexanone by Pd supported on alumina than carbon supported catalysts. They concluded the support material is important to the activity and selectivity. The turn over frequency (TOF) of phenol hydrogenation increased with the Pd dispersion. The selectivity of the reaction to cyclohexanone increased from $78 \%$ to $98 \%$ using $\mathrm{Pd} / \mathrm{Al}_{2} \mathrm{O}_{3}$ catalyst with $\mathrm{Pd}$ content from 18.5 to 63.7 , respectively. The study proved that activity is a direct function of the metal content. Even though their phenol solvent was water, and their reaction time was short, Perez et al. used high hydrogen pressure of 5 bar. Most importantly, the support was a ceramic material that is brittle and can break into small parts in the liquid phase. This adds a filtration step to remove the catalyst from products. Also, ceramic supports have low mechanical flexibility, which makes it difficult to use in a multiphase flow reactor. Recent studies have shown that metal particles supported on polymer nanofiber mats produced by the electrospinning technique show good catalytic activities [25,26]. For example, Demir's group utilized electrospun palladium particles with poly(acrylonitrile-co-acrylic acid) to produce a catalytic fiber mat. The mat was used to selectively hydrogenate dehydrolinalool. The electrospun $\mathrm{Pd} /$ polymer catalyst showed 4.5 times higher activity than $\mathrm{Pd} / \mathrm{Al}_{2} \mathrm{O}_{3}$ supports. It was concluded that catalytic particles supported on electrospun polymer nanofibers performed better than using those supported on inorganic supports in organic reactions [26].

It is thus of great interest to prepare Pd supported on polymer support for multiphase hydrogenation of phenol. The electrospun fiber mat catalysts have the advantages of good mechanical strength, high porosity, high permeability, and other improved characteristics. In contrast to nanopowder or nanoparticles on the ceramic catalyst, the polymer catalytic membranes are very easy to separate from liquid phase products. Most importantly, the polymeric membrane catalysts can be used in different continuous flow reactors like membrane reactors, packed bed reactors or fluidized bed reactors.

In the present work, palladium nanoparticles were immobilized on PVDF-HFP (poly(vinylidene fluoride-co-hexafluoropropylene)) fiber mats using electrospinning. The fiber mat was characterized using different catalytic characterization techniques. PVDF-HFP was chosen because it is a semicrystalline polymer that has been used as a catalytic support. It is an inert, superhydrophobic polymer, and it has great chemical and mechanical characteristics [27-36].

\section{Materials and Methods}

\subsection{Preparation of Pd/PVDF-HFP Catalyst}

The PVDF-HFP with a molecular weight of 450,000 (Detonated by Arkema, Inc., King of Prussia, PA, USA) was dissolved in acetone (Sigma Aldrich, St. Louis, MO, USA) at room temperature to form electrospinning solutions having polymer concentrations of $10 \mathrm{wt} \%$. Mild stirring for $24 \mathrm{~h}$ was done to make the electrospinning solutions. Then $0.3 \mathrm{~g}$ of palladium black (Sigma Aldrich) was added into $15 \mathrm{~mL}$ of the prepared PVDF-HFP solution and mixed for one day to disperse the catalytic metal particles uniformly in the polymer solution. Electrospinning of the PVDF-HFP solution containing 
Pd particles was executed at room temperature where the prepared solution was injected from a $5 \mathrm{~mL}$ syringe equipped with a 21-gauge needle through a syringe pump (SP220i, World Precision Instruments, Sarasota, FL, USA) at a feed rate of $15 \mathrm{~mL} / \mathrm{h}$ [31]. The power supply was adjusted to $30 \mathrm{kV}$. A piece of aluminum foil was used as a collector for the produced fibers. The gap distance between the needle and the aluminum foil was $15 \mathrm{~cm}$.

\subsection{Catalytic Membrane Characterization}

The thermal properties of the electrospun catalytic membrane were analyzed with a thermogravimetric analyzer (TGAQ500) (TA Instruments, New Castle, DE, USA). TGA analysis was performed in the temperature range of $30-800{ }^{\circ} \mathrm{C}$ with a $20{ }^{\circ} \mathrm{C} / \mathrm{min}$ heating rate under $\mathrm{N}_{2}$. In addition, the electrospun catalytic membrane was placed in a furnace, Barnstead Thermolyne 1400 Furnace, at $120^{\circ} \mathrm{C}$ under air conditioning for $12 \mathrm{~h}$ to measure the weight change. Scanning electron microscopy (SEM) was used to study the fiber morphology. SEM images of the catalytic membrane were acquired using FEI Quanta 200 at $15 \mathrm{kV}$ and HITACHI TM3000 (Hitachi High Technologies America, Inc, Greenville, SC, USA). The images were taken with different magnifications at the voltage of $15 \mathrm{kV}$. The diameter of the nanofibers was measured directly from the SEM images using FibraQuant 1.3 software (nanoScaffold Technologies LLC, Chapel Hill, NC, USA) and was displayed as diameter histogram. The histogram was generated out of 100 measurements. Transmission Electron Microscope (TEM, JEM 1200XII, Jeol USA, Peabody, MA, USA) was used to acquire the catalytic particle size. To prepare the TEM sample, the fibers were directly dispersed on a TEM grid during electrospinning. An X-ray diffractometer (Bruker AXS Dimension D8 X-ray, BRUKER AXS, Inc. Madison, WI, USA) was used to determine the support and catalytic peaks. PVDF-HFP with and without catalytic particles was tested. $\mathrm{Cu}$ anode $(\mathrm{K} \alpha 1=0.154056 \mathrm{~nm})$ was used. The voltage was set to $40 \mathrm{kV}$ and the current to $40 \mathrm{~mA}$. Scans were collected with the step size of 0.1 degrees and scan speed of 0.5 degrees $/ \mathrm{min}$. The wettability of the membrane was characterized by the water contact angle. Water drops of $5 \mu \mathrm{L}$ volumes were placed on the fiber mats and imaged using a drop shape analyzer (DSA20E, Krüss $\mathrm{GmbH}$, Hamburg, Germany). To determine the contact angle, the contact angles were averaged from measurements of five independent drops. Frazier Air Permeability Tester (Frazier Precision Instrument Company, Inc., Hagerstown, MD, USA) was used to measure the permeability of the catalytic membrane. The permeability can be calculated using Darcy's law. Darcy's law provides a relationship between the pressure drop and the flow through a membrane with the permeability coefficient as given in Equation (1):

$$
Q=k A(P o-P l) / \mu L
$$

where $k$ is the permeability in $\mathrm{m}^{2}, P o$ and $P l$ are the initial and final pressure in $\mathrm{Pa}, L$ is the thickness of the membrane in $\mathrm{m}, Q$ is the volumetric flow rate in $\mathrm{m}^{3} / \mathrm{s}, \mu$ is the kinematic viscosity in $\mathrm{NS} / \mathrm{m}^{2}$, and $A$ is the area of the membrane in $\mathrm{m}$. For thin media, as for the tested catalytic PVDF-HFP membrane, to obtain accurate permeability values, an accurate measure of the mat thickness is very important. Since, precise thickness measurements were not obtainable hence, the ratio of permeability to the thickness of the medium is reported for this work.

\subsection{Catalytic Experiments}

In a typical reaction, aqueous phenol $(20 \mathrm{~g} / \mathrm{L})$ was first prepared by dissolving phenol in deionized water. Seventy-five $\mathrm{mL}$ of the phenol and different amounts of Pd/PVDF-HFP catalyst (5, 10, and $15 \mathrm{wt} \%$ of palladium relative to phenol), was placed into a three-necked flask in three different experiments. A balloon was connected to the flask to store the hydrogen. Prior to the reaction, the system was flushed with hydrogen three times to remove air. The mixing and heating of reactants were conducted using a magnetic stirrer with a hotplate. The temperature of the system was raised to $80^{\circ} \mathrm{C}$. After a period of time, a sample was taken and analyzed to monitor the progress of the reaction. The 
reaction products were analyzed using a gas chromatograph (Shimadzu GC-17A, Shimadzu America Inc., Columbia, MD, USA) equipped with a Flame Ionization Detector (FID) and Hewlett Packard free fatty acids phase (HP-FFAP) column. The GC conditions were as follows: Injection temperature, $220{ }^{\circ} \mathrm{C}$; detector temperature, $240{ }^{\circ} \mathrm{C}$; column temperature, $120{ }^{\circ} \mathrm{C}$; and temperature ramping rate, $10^{\circ} \mathrm{C} / \mathrm{min}[20]$. The conversion of cyclohexanone into products was calculated using

$$
\text { Conversion } X_{A}=\frac{C_{A 0}-C_{A}}{C_{A 0}}
$$

where $C_{A 0}$ and $C_{A}$ are initial and final cyclohexanone concentrations, respectively.

\section{Results and Discussion}

\subsection{Pd/PVDF-HFP Characterization}

Figure 1 shows photos of the PVDF-HFP fiber mat with (B) and without (A) spinning catalytic particles in the polymer solution. A clear color change was observed when adding the catalytic nanoparticles. This indicates that the nanoparticles are not agglomerated but homogenously dispersed on the surface of the membrane and expected to have catalytic active sites all over the membrane.

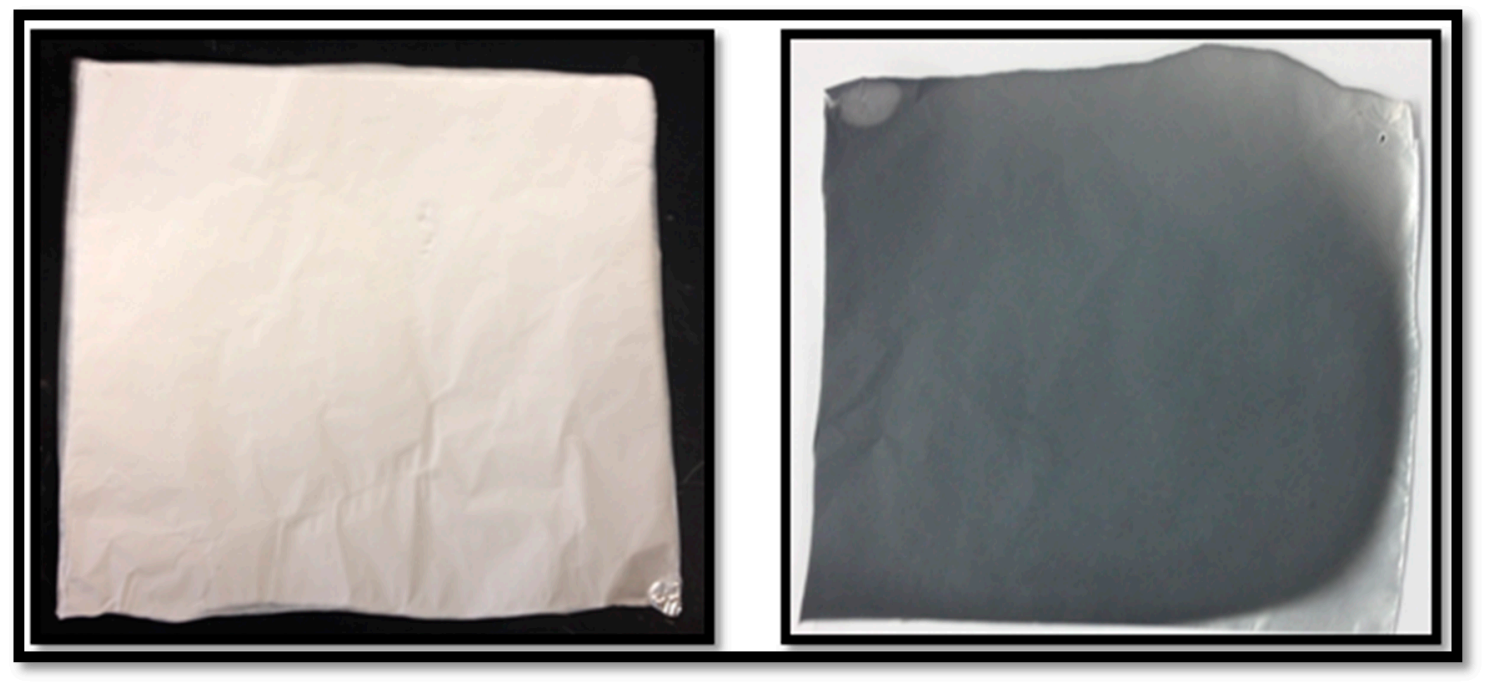

(A)

(B)

Figure 1. Polyvinylidene fluoride-co-hexafluoropropylene (PVDF-HFP) electrospun fiber mat (A) without and (B) with catalytic nanoparticles.

The TGA curve presented in Figure 2 shows that the PVDF-HFP catalytic membrane started degradation at around $420^{\circ} \mathrm{C}$. The PVDF-HFP membranes with and without catalyst have similar thermal properties. There was also no weight change for the sample that was placed in the furnace for $12 \mathrm{~h}$. It was thus very safe to operate the reaction at $80^{\circ} \mathrm{C}$.

The fiber morphology was achieved using SEM as shown in Figure 3. The mean fiber diameter was around $357 \pm 118 \mathrm{~nm}$, and the mats have some beads.

The TEM image shown in Figure 4 exhibits Pd particles dispersion on PVDF-HFP fibers. The average particle size was around $20 \mathrm{~nm}$. 


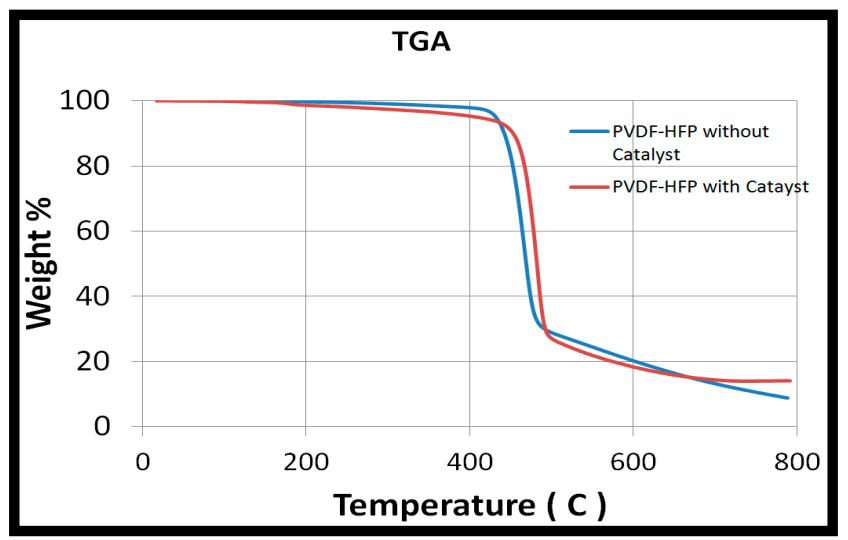

Figure 2. Thermogravimetric analyzer (TGA) analysis of PVDF-HFP nanofibers.
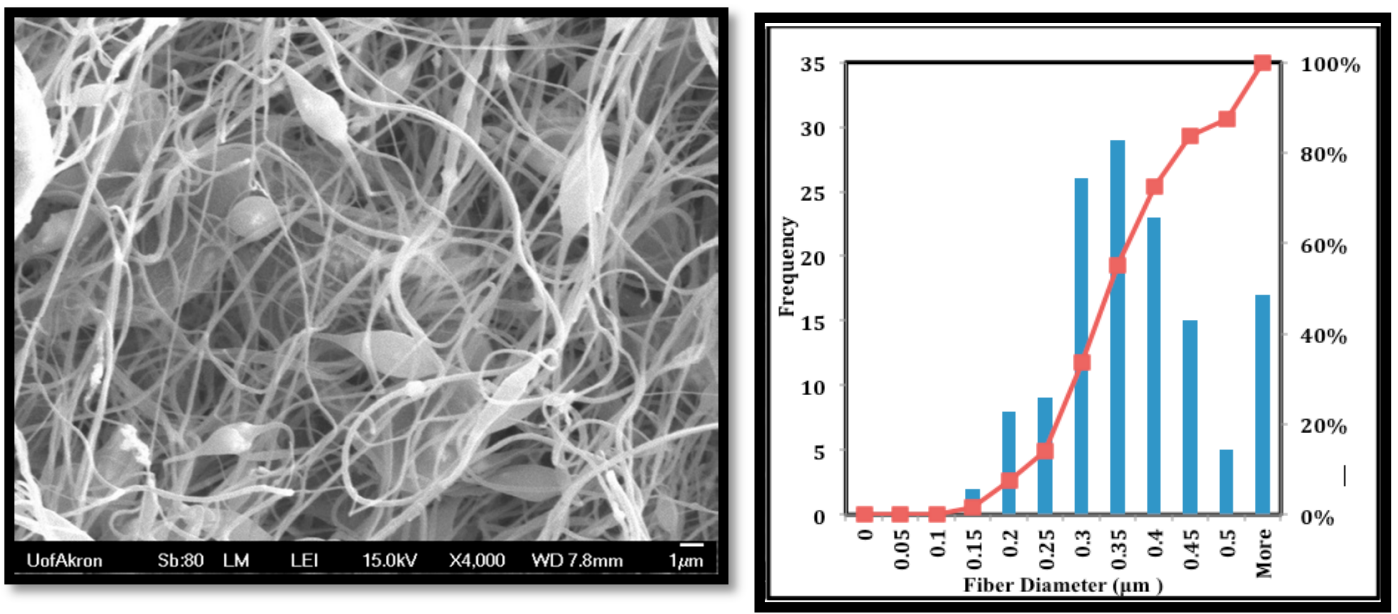

Figure 3. Scanning electron microscopy (SEM) images of the PVDF-HFP nanofibers.

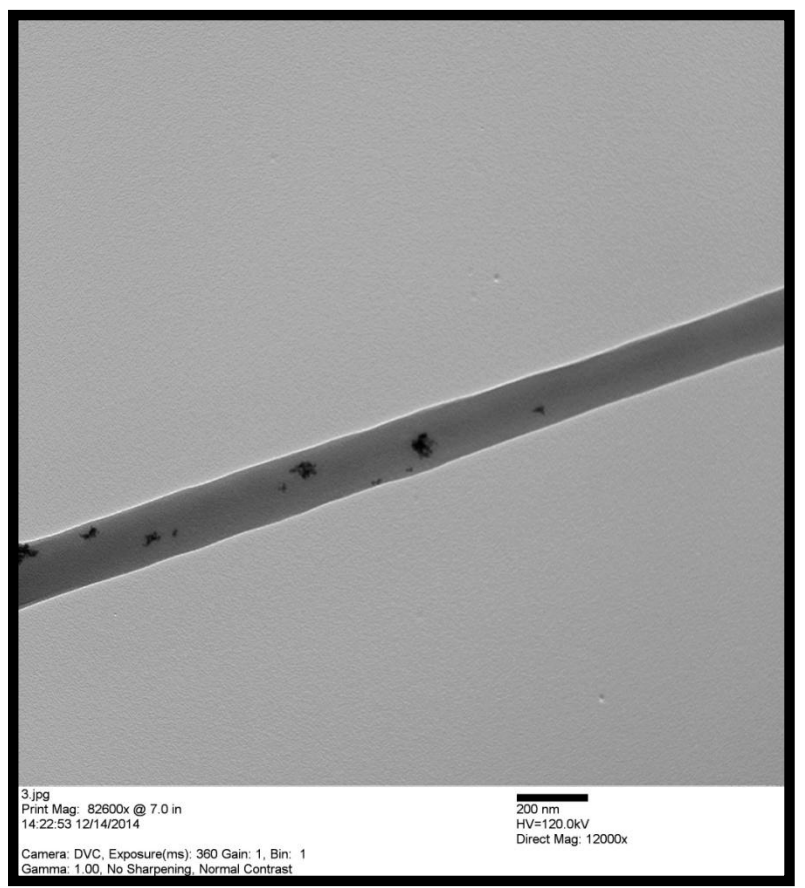

Figure 4. Transmission electron microscope (TEM) image of Pd/PVDF-HFP nanofibers. 
X-ray diffraction (XRD) peaks as shown in Figure 5 showed that peaks before 40 degrees are related to the polymer support, and peaks after 40 degrees are related to the catalyst. Peaks at $2 \theta=41^{\circ}$, $47^{\circ}$, and $68^{\circ}$ represent the indices of (111), (200), and (222) crystal planes of Pd [37-39], respectively.

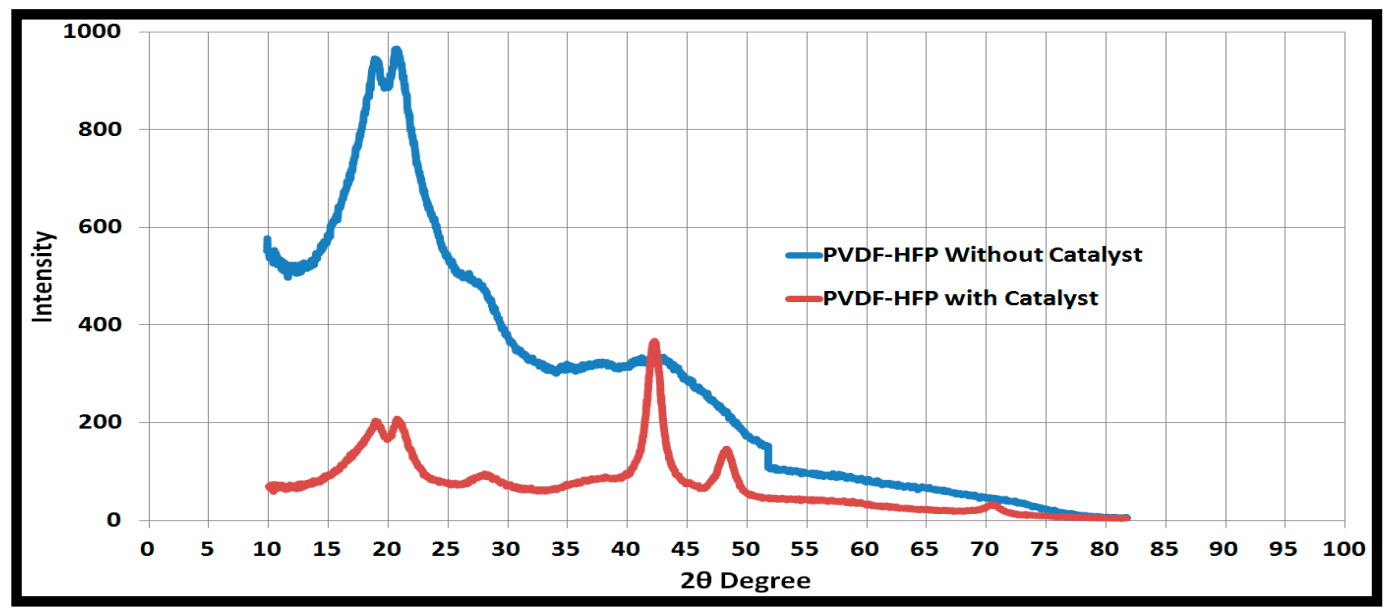

Figure 5. X-Ray Defraction (XRD) plots of PVDF-HFP with and without catalytic nanoparticles.

The contact angle of the catalytic media was 145 with respect to aqueous phenol as shown in Figure 6. The permeability of the catalyst calculated over the thickness of the fiber mat was $\frac{k}{l}=4.4363 \times 10^{-9} \mathrm{~m}$.

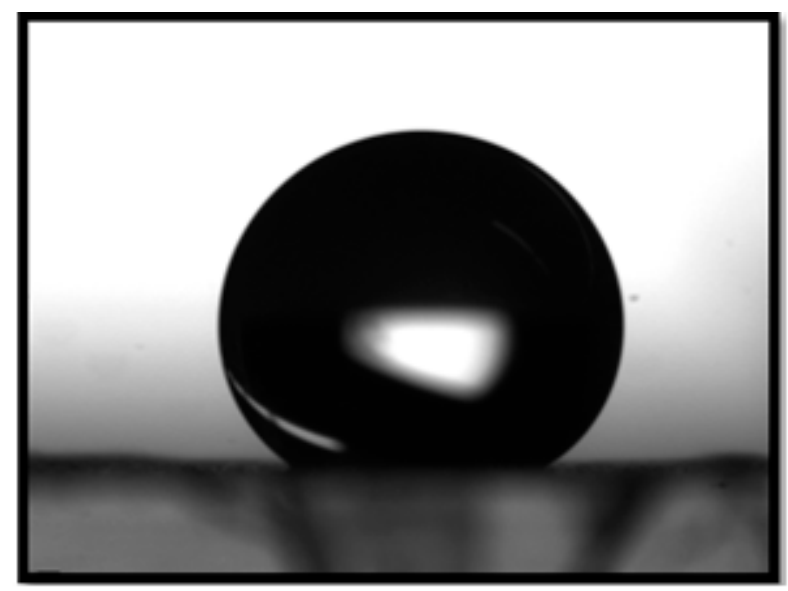

Figure 6. Contact angle of aqueous phenol with respect to PVDF-HFP membrane.

\subsection{Pd/PVDF-HFP Catalytic Performance Test}

Different amounts of Pd/PVDF-HFP catalysts were tested. First, $10 \mathrm{wt} \%$ of palladium with respect to phenol (1.5 g phenol and $0.15 \mathrm{gPd} / 0.75 \mathrm{gPVDF}-\mathrm{HFP})$ was tested. Conversion of phenol increased with time and was $37 \%$ in $3 \mathrm{~h}$ and $62 \%$ in $7 \mathrm{~h}$ as shown in Figure 7 . Only cyclohexanone was detected at the first three hours indicating $100 \%$ selectivity. The cyclohexanone selectivity was decreased slightly to $99 \%$ at $6 \mathrm{~h}$ and to $98 \%$ at $7 \mathrm{~h}$. To have a higher conversion, the amount of palladium was increased to $15 \mathrm{wt} \%$ with respect to phenol (1.5 g phenol and $0.225 \mathrm{gPd} / 1.125 \mathrm{~g}$ PVDF-HFP). The phenol conversion achieved was $60 \%$ in $3 \mathrm{~h}$ and $88 \%$ in $6 \mathrm{~h}$. Almost complete phenol conversion was achieved at $7 \mathrm{~h}(98 \%)$ as shown in Figure 8. The TON (turnover number) and TOF (turnover frequency) values calculated were 7.38 and $1.05 \mathrm{~h}^{-1}$, respectively. The TON value was calculated based on the moles of phenol converted (0.0159 moles) with respect to moles of Pd utilized (0.0021) in the reaction while TON with respect to time of reaction was termed as TOF [40]. 


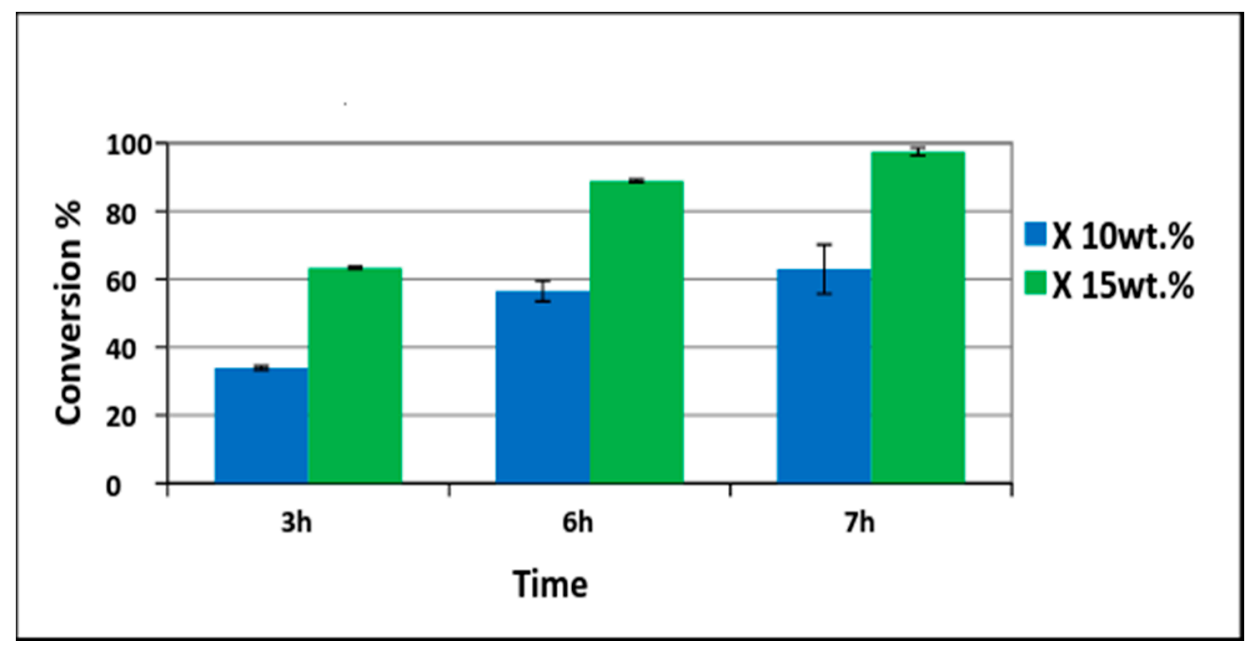

Figure 7. Conversion of phenol using $10 \mathrm{wt} \%$ (phenol $1.5 \mathrm{~g}$ (0.0159 moles) with palladium $0.15 \mathrm{~g}$ (0.0014 moles) ) and $15 \mathrm{wt} \%$ (phenol $1.5 \mathrm{~g}$ (0.0159 moles) with palladium $0.225 \mathrm{~g}(0.0021 \mathrm{moles}))$ of electrospun catalysts.

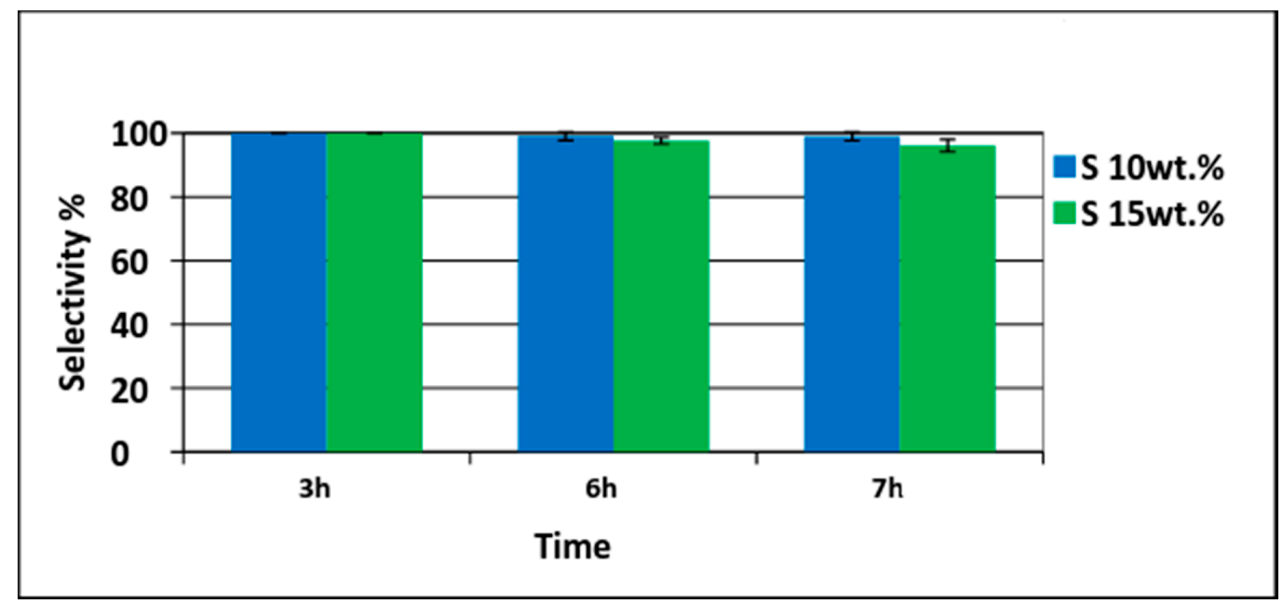

Figure 8. Selectivity of cyclohexanone using $10 \mathrm{wt} \%$ (phenol $1.5 \mathrm{~g}$ (0.0159 moles) with palladium $0.15 \mathrm{~g}$ (0.0014 moles) ) and $15 \mathrm{wt} \%$ (phenol $1.5 \mathrm{~g}$ (0.0159 moles) with palladium $0.225 \mathrm{~g}$ (0.0021 moles)) of electrospun catalysts.

The selectivity of cyclohexanone achieved was very high ( $>95 \%)$ even at high phenol conversion as shown in Figure 8. The result proved that phenol conversion could be increased by increasing the metal loading without a major decrease in the desired selectivity when using superhydrophobic nanofiber support. The high cyclohexanone selectivity is attributed to the superhydrophobicity of the PVDF-HFP support.

\section{Conclusions}

Hydrogenation of phenol to cyclohexanone was achieved actively and selectively using nanofiber supported catalysts. Palladium nanoparticles supported on PVDF-HFP nanofibers were synthesized using electrospinning. The superhydrophobic catalytic fiber mats directed the reaction toward the desired product leading to high cyclohexanone selectivity and high phenol conversion. The conversion of phenol achieved was $98 \%$ with $97 \%$ cyclohexanone selectivity within $7 \mathrm{~h}$ using $15 \mathrm{wt} \%$ of palladium relative to phenol. This paper presents novel research in heterogeneous catalysis using electrospun nanofibers. Multiphase hydrogenation of phenol to cyclohexanone over electrospun Pd/PVDF-HFP catalyst has not been reported earlier in the literature. This work can open a research window for 
applications of polymeric nanofibers in multiphase reactions. The polymeric structure provided the advantages of easy separation and high mechanical strength.

Author Contributions: Reaction experiment, original draft preparation, A.A. (Ahmed Abutaleb); characterization and analysis, D.L., A.A. (Abdulwahab Aljuhani) and H.U.S.; partial writing, review and editing, M.A.A.; writing and editing, A.A.Y.H. and I.M.H.M.; advising and supervision, G.G.C.

Funding: This research received external funding.

Acknowledgments: The author would like to thank SABIC Company and Jazan University for financially supporting this project (Grant No. SABIC 3/2018/1). Special thanks go to Arkema for denoting the PVDF-HFP polymer.

Conflicts of Interest: The authors declare no conflict of interest.

\section{References}

1. Liu, H.; Jiang, T.; Han, B.; Liang, S.; Zhou, Y. Selective phenol hydrogenation to cyclohexanone over a dual supported Pd-Lewis acid catalyst. Science 2009, 326, 1250-1252. [CrossRef]

2. Xiang, Y.; Ma, L.; Lu, C.; Zhang, Q.; Li, X. Aqueous system for the improved hydrogenation of phenol and its derivatives. Green Chem. 2008, 10, 939-943. [CrossRef]

3. Fujita, S.; Yamada, T.; Akiyama, Y.; Cheng, H.; Arai, M. Hydrogenation of phenol with supported Rh catalysts in the presence of compressed $\mathrm{CO}_{2}$ : Its effects on reaction rate, product selectivity and catalyst life. J. Supercrit. Fluids 2010, 54, 190-201. [CrossRef]

4. Hu, S.; Yang, G.; Jiang, H.; Liu, Y.; Chen, R. Selective hydrogenation of phenol to cyclohexanone over Pd@CN (N-doped porous carbon): Role of catalyst reduction method. Appl. Surf. Sci. 2018, 435, 649-655. [CrossRef]

5. Cheng, H.; Liu, R.; Wang, Q.; Wu, C.; Yu, Y.; Zhao, F. Selective reduction of phenol derivatives to cyclohexanones in water under microwave irradiation. New J. Chem. 2012, 36, 1085-1090. [CrossRef]

6. Yang, X.; Du, L.; Liao, S.; Li, Y.; Song, H. High-performance gold-promoted palladium catalyst towards the hydrogenation of phenol with mesoporous hollow spheres as support. Catal. Commun. 2012, 17, $29-33$. [CrossRef]

7. Ribeiro, A.P.C.; Martins, L.M.D.R.S.; Pombeiro, A.J.L. $\mathrm{N}_{2} \mathrm{O}$-Free single-pot conversion of cyclohexane to adipic acid catalysed by an iron(II) scorpionate complex. Green Chem. 2017, 19, 1499-1501. [CrossRef]

8. Martins, L.M.D.R.S.; Pombeiro, A.J.L. Tris(pyrazol-1-yl)methane metal complexes for catalytic mild oxidative functionalizations of alkanes, alkenes and ketones. Coord. Chem. Rev. 2014, 265, 74-88. [CrossRef]

9. Sikhwivhilu, L.M.; Coville, N.J.; Naresh, D.; Chary, K.V.R.; Vishwanathan, V. Nanotubular titanate supported palladium catalysts: The influence of structure and morphology on phenol hydrogenation activity. Appl. Catal. A Gen. 2007, 324, 52-61. [CrossRef]

10. Ding, S.; Zhang, C.; Liu, Y.; Jiang, H.; Chen, R. Selective hydrogenation of phenol to cyclohexanone in water over Pd@N-doped carbons derived from ZIF-67: Role of dicyandiamide. Appl. Surf. Sci. 2017, 425, 484-491. [CrossRef]

11. Yang, X.; Yu, X.; Long, L.; Wang, T.; Ma, L.; Wu, L.; Bai, Y.; Li, X.; Liao, S. Pt nanoparticles entrapped in titanate nanotubes (TNT) for phenol hydrogenation: the confinement effect of TNT. Chem. Commun. 2014, 50, 2794-2796. [CrossRef]

12. Li, H.; Liu, J.; Li, H. Liquid-phase selective hydrogenation of phenol to cyclohexanone over the Ce-doped Pd-B amorphous alloy catalyst. Mater. Lett. 2008, 62, 297-300. [CrossRef]

13. Wang, H.; Zhao, F.; Fujita, S.; Arai, M. Hydrogenation of phenol in $\mathrm{scCO}_{2}$ over carbon nanofiber supported Rh catalyst. Catal. Commun. 2008, 9, 362-368. [CrossRef]

14. Chatterjee, M.; Kawanami, H.; Sato, M.; Chatterjee, A.; Yokoyama, T.; Suzuki, T. Hydrogenation of Phenol in Supercritical Carbon Dioxide Catalyzed by Palladium Supported on Al-MCM-41: A Facile Route for One-Pot Cyclohexanone Formation. Adv. Synth. Catal. 2009, 351, 1912-1924. [CrossRef]

15. Velu, S.; Kapoor, M.P.; Inagaki, S.; Suzuki, K. Vapor phase hydrogenation of phenol over palladium supported on mesoporous $\mathrm{CeO}_{2}$ and $\mathrm{ZrO}_{2}$. Appl. Catal. A Gen. 2003, 245, 317-331. [CrossRef]

16. Xu, T.; Zhang, Q.; Cen, J.; Xiang, Y.; Li, X. Selectivity tailoring of Pd/CNTs in phenol hydrogenation by surface modification: Role of CO oxygen species. Appl. Surface Sci. 2015, 324, 634-639. [CrossRef] 
17. Makowski, P.; Cakan, R.D.; Antonietti, M.; Goettmann, F.; Titirici, M.-M. Selective partial hydrogenation of hydroxy aromatic derivatives with palladium nanoparticles supported on hydrophilic carbon. Chem. Commun. 2008, 8, 999-1001. [CrossRef]

18. Wang, Y.; Yao, J.; Li, H.; Su, D.; Antonietti, M. Highly selective hydrogenation of phenol and derivatives over a Pd@carbon nitride catalyst in aqueous media. J. Am. Chem. Soc. 2011, 133, 2362-2365. [CrossRef] [PubMed]

19. Shin, H.U.; Lolla, D.; Nikolov, Z.; Chase, G.G. Pd-Au nanoparticles supported by $\mathrm{TiO}_{2}$ fibers for catalytic NO decomposition by CO. J. Ind. Eng. Chem. 2016, 33, 91-98. [CrossRef]

20. Liu, J.; Li, H.; Li, H. Liquid-Phase Selective Hydrogenation of Phenol to Cyclohexanone over Pd-Ce-B/ Hydrotalcite Catalyst. Chin. J. Catal. 2007, 28, 312-316. [CrossRef]

21. Mahata, N.; Vishwanathan, V. Influence of Palladium Precursors on Structural Properties and Phenol Hydrogenation Characteristics of Supported Palladium Catalysts. J. Catal. 2002, 196, 262-270. [CrossRef]

22. Sulman, E.M.; Ivanov, A.A.; Chernyavsky, V.S.; Sulman, M.G.; Bykov, A.I.; Sidorov, A.I.; Doluda, V.Y.; Matveeva, V.G.; Bronstein, L.M.; Stein, B.D. Kinetics of phenol hydrogenation over Pd-containing hypercrosslinked polystyrene. Chem. Eng. J. 2011, 33, 176-177. [CrossRef]

23. Matos, J.; Corma, A. Selective phenol hydrogenation in aqueous phase on Pd-based catalysts supported on hybrid $\mathrm{TiO}_{2}$-carbon materials. Appl. Catal. A Gen. 2011, 404, 103-112. [CrossRef]

24. Pérez, Y.; Fajardo, M.; Corma, A. Highly selective palladium supported catalyst for hydrogenation of phenol in aqueous phase. Catal. Commun. 2011, 12, 1071-1074. [CrossRef]

25. Demir, M.M.; Gulgun, M.A.; Menceloglu, Y.Z.; Erman, B.; Yolu, R.; Abramchuk, S.S.; Makhaeva, E.E.; Matveeva, A.R.; Sulman, M.G. Palladium Nanoparticles by Electrospinning from Poly(acrylonitrile-co-acrylic acid) $-\mathrm{PdCl}_{2}$ Solutions. Relations between Preparation Conditions, Particle Size, and Catalytic Activity. Macromolecules 2004, 37, 1787-1792. [CrossRef]

26. Huang, Y.; Ma, H.; Wang, S.; Shen, M.; Guo, R.; Cao, X.; Zhu, M.; Shi, X. Efficient catalytic reduction of hexavalent chromium using palladium nanoparticle-immobilized electrospun polymer nanofibers. ACS Appl. Mater. Interfaces 2012, 4, 3054-3061. [CrossRef]

27. Reverchon, E.; Cardea, S. PVDF-HFP Membrane Formation by Supercritical $\mathrm{CO}_{2}$ Processing: Elucidation of Formation Mechanisms. Ind. Eng. Chem. Res. 2006, 45, 8939-8945. [CrossRef]

28. Cardea, S.; Reverchon, E. Nanostructured PVDF-HFP membranes loaded with catalyst obtained by supercritical $\mathrm{CO}_{2}$ assisted techniques. Chem. Eng. Process Process Intensif. 2011, 50, 630-636. [CrossRef]

29. Priya, A.R.S.; Subramania, A.; Jung, Y.; Kim, K. High-performance quasi-solid-state dye-sensitized solar cell based on an electrospun PVdF-HFP membrane electrolyte. Langmuir 2008, 24, 9816-9819. [CrossRef] [PubMed]

30. Ye, H.; Huang, J.; Xu, J.J.; Khalfan, A.; Greenbaum, S.G. Li Ion Conducting Polymer Gel Electrolytes Based on Ionic Liquid/PVDF-HFP Blends. J. Electrochem. Soc. 2007, 154, A1048-A1057. [CrossRef] [PubMed]

31. Patel, S.U.; Patel, S.U.; Chase, G.G. Electrospun superhydrophobic poly(vinylidene fluoride-cohexafluoropropylene) fibrous membranes for the separation of dispersed water from ultralow sulfur diesel. Energy Fuels 2013, 27, 2458-2464. [CrossRef]

32. Carlin, R.T.; Fuller, J. Ionic liquid-polymer gel catalytic membrane. Chem. Commun. 1997, 1345-1346. [CrossRef]

33. Huang, Z.M.; Zhang, Y.Z.; Kotaki, M.; Ramakrishna, S. A review on polymer nanofibers by electrospinning and their applications in nanocomposites. Compos. Sci. Technol. 2003, 63, 2223-2253. [CrossRef]

34. Chronakis, I.S. Novel nanocomposites and nanoceramics based on polymer nanofibers using electrospinning process-A review. J. Mater. Process Technol. 2005, 167, 283-293. [CrossRef]

35. Teo, W.E.; Ramakrishna, S. A review on electrospinning design and nanofibre assemblies. Nanotechnology 2006, 17, R89-R106. [CrossRef] [PubMed]

36. Frenot, A.; Chronakis, I.S. Polymer Nanofibers Assembled by Electrospinning. Curr. Opin. Colloid Interface Sci. 2003, 8, 64-75. [CrossRef]

37. Park, S.J. Catalytic Decomposition of Nitric Oxide and Carbon Monoxide Gases Using Nanofiber Based Filter Media. Ph.D. Dissertation, The University of Akron, Akron, OH, USA, August 2008.

38. Fan, L.; Zhang, L.; Shen, Y.; Liu, D.; Wahab, N.; Hasan, M.M. Liquid-phase Hydrogenation of Phenol to Cyclohexanone over Supported Palladium Catalysts. Bull. Chem. Reac. Eng. Catal. 2016, 11, 354-360. [CrossRef] 
39. Chen, A.; Li, Y.; Chen, J.; Zhao, G.; Ma, L.; Yu, Y. Selective Hydrogenation of Phenol and Derivatives over Polymer-Functionalized Carbon-Nanofiber-Supported Palladium Using Sodium Formate as the Hydrogen Source. ChemPlusChem 2013, 78, 1370-1378. [CrossRef]

40. Kozuch, S.; Martin, J.M.L. “Turning Over" Definitions in Catalytic Cycles. ACS Catal. 2012, 2, $2787-2794$. [CrossRef] 